Article

\title{
Regional Development Quality of Yangtze River Delta: From the Perspective of Urban Population Agglomeration and Ecological Efficiency Coordination
}

\author{
Zhenxiao $\mathrm{Xu}^{1}$ and Yongqiang Yin ${ }^{2, *}$ \\ 1 Alibaba Business School, Hangzhou Normal University, Hangzhou 311121, China; xuzhenxiao@hznu.edu.cn \\ 2 School of Economics, Hangzhou Normal University, Hangzhou 311121, China \\ * Correspondence: yinyongqiang7@163.com
}

Citation: Xu, Z.; Yin, Y. Regional Development Quality of Yangtze River Delta: From the Perspective of Urban Population Agglomeration and Ecological Efficiency

Coordination. Sustainability 2021, 13, 12818. https://doi.org/10.3390/ su132212818

Academic Editor: Tan Yigitcanlar

Received: 19 October 2021

Accepted: 18 November 2021

Published: 19 November 2021

Publisher's Note: MDPI stays neutral with regard to jurisdictional claims in published maps and institutional affiliations.

Copyright: (C) 2021 by the authors. Licensee MDPI, Basel, Switzerland. This article is an open access article distributed under the terms and conditions of the Creative Commons Attribution (CC BY) license (https:/ / creativecommons.org/licenses/by/ $4.0 /)$.

\begin{abstract}
With the deepening of the development process of regional integration in the Yangtze River Delta, integration and high quality have become the key paths of regional development. On the basis of the panel data of 26 cities in the Yangtze River Delta urban agglomeration, from 2008 to 2018, this paper uses a DEA model to calculate the ecological efficiency of each city. On the basis of the visual expression of the population agglomeration degree, with the help of ArcGIS platform, the coupling coordination between the population agglomeration and the ecological efficiency is calculated by using the coupling degree model. The results show the spatiotemporal pattern changes of the coupling coordination degrees of 26 cities in the Yangtze River Delta urban agglomeration between population agglomeration and ecological environment, modeling the impact of urban population growth on the ecological environment. The research provides a scientific basis for determining the goal of urban population development, for coordinating the relationship between populations and the environment in urban development, and for realizing regional sustainable and high-quality development.
\end{abstract}

Keywords: population agglomeration; ecological efficiency; coordination; Yangtze River Delta region; development quality

\section{Introduction}

Urbanization is not only a process, but also the product of social and economic development to a certain stage. It presents different characteristics in different stages: slow growth in the initial stage, rapid growth in the middle stage, mature development in the later stage, and stable development in the final stage.

After 72 years of tortuous development, China's urbanization has entered a stage of rapid development in the last 20 years and has made remarkable achievements. Although China's urbanization level has exceeded the world average urbanization level, the gap between cities is widening. Some cities even fall into subhealth statuses. Moreover, the challenges between resource supply bottlenecks and environmental protection turn out to be increasingly severe in the process of rapid urbanization.

As one of the four subsystems of urbanization, the impact of population urbanization on the urban ecological environment is mainly represented in two aspects: First, affected by the expansion of urban space, and the rapid expansion of the population, the population density in urban areas is increasing, which results in rising energy consumption for production and life. In addition, the emissions of pollutants is also increasing sharply without significant improvement in pollution control, resulting in increasingly prominent environmental problems, such as ecological deterioration, intensified urban environmental pollution, insufficient greening infrastructure construction, and so on. Second, population agglomeration brings a large number of technicians to the city. The agglomeration effect 
of human capital promotes the progress of pollution control technology, reduces pollutant discharges, and improves pollutant treatment efficiency, so as to improve the urban ecological environment.

The Yangtze River Delta urban agglomeration is one of the most active areas in China's economic development, and it is also one of the most active areas in China's economic development, with the highest degree of urban agglomeration and the largest number of migrant populations. Currently, integrated high-quality regional development models have not been fully implemented, which will inevitably increase the pressure on resources and the environment. In this context, the coordination of population agglomeration and urban ecological efficiency is studied. It is of great significance that the increase in the population and the ecological balance achieve regional high-quality development.

From the perspective of population urbanization, this research explores the stages and couplings of the interaction between urban population agglomeration and urban ecological efficiency in the process of urbanization. Urban population density is used to express the degree of population aggregation, and data envelopment analysis (DEA) is used to measure urban ecological efficiency. By selecting specific evaluation indicators, and through the dimensionless processing of the data, the values of the population agglomeration and the ecological efficiency are calculated. The coupling degree and coordination degree of population agglomeration and ecological efficiency are calculated by using the coupling coordination degree model. The coupling degree judges the strength of the interaction, which is used to measure the relationship between the two system components. The coordination degree is used to characterize whether the system components promote each other at a high level or restrict each other at a low level. On the basis of the data, the research analyzes the spatiotemporal pattern changes of the coupling and coordination of the population agglomeration and the ecological environment in 26 cities of the Yangtze River Delta urban agglomeration, so as to reveal the change law of the pressure on the ecological environment from urban population growth, and then provides a scientific reference for the goal of urban population development, coordinating the relationship between the population and the environment in urban development, with the aim of achieving regional sustainable and high-quality development.

The research shows that population agglomeration is not the main reason for the low ecological efficiencies of some cities in the Yangtze River Delta urban agglomeration. In terms of the time series, the coupling coordination degrees showed an overall upward trend, and the population and ecological elements gradually coordinated and cooperated with each other, formed a virtuous circle, and approached the direction of high-level mutual promotion. From the perspective of the spatial dimension, there are distinct differences in the coupling coordinations among cities, and the coupling coordination degrees of some cities are still relatively low.

\section{Literature Review}

Sustainable development goals involve three aspects: economic growth, social equity, and ecological protection [1]. There are two areas of high concern in the process of urbanization: one is the development of the city itself, and the second is the impact of urbanization on the ecological environment. The most prominent manifestation of urbanization is the increasing proportion of the urban population.

Population agglomeration can be expressed by population density. Reflecting the size of the regional population scale is one of the most important bases for measuring urbanization. The research on population agglomeration mainly focuses on the following aspects: First, on the temporal and spatial characteristics of the population agglomeration. With the change of the spatial structure of China's economic development, there are significant spatial differences in population agglomerations. The population agglomerations present the spatial characteristics of high in the east, low in the middle, and the lowest in the west, as well as the time differentiations of the increasing urban population agglomerations and the decreasing rural suburbs over time [2]. The second aspect refers to research on the influ- 
encing factors of population agglomeration, including economic factors [3], urbanization levels [4], etc. The third aspect refers to the relationship between population agglomeration and economic development. The most direct manifestation of population agglomeration is the increase in human capital, promoting technological progress and increasing labor productivity [5].

Ecoefficiency aims to improve urban efficiency while reducing the load on the urban ecosystem. It is a comprehensive manifestation of environmental, resource, and economic elements, which can reflect the basic situation of resource utilization and environmental protection. The concept of ecological efficiency was proposed in the 1990s by Schaltegger and Sturnis [6], and it has received extensive attention from the World Business Council for Sustainable Development (WBCSD) [7], and the Organization for Economic Co-operation and Development (OECD) [8]. For the calculation method of ecological efficiency, there is the single ratio method $[9,10]$, the indicator evaluation method $[11,12]$, the model method $[13,14]$, etc. Subsequent scholars also improve and build out from existing methods and models $[15,16]$. Currently, data envelopment analysis (DEA) is the most widely used method for measuring ecoefficiency, and it is also the method used to measure urban ecoefficiency in this paper. DEA is a mature linear programming method, which was proposed by Charnes et al. (1978) [17], and was further applied to measure the relative efficiency of equivalent decision-making units, with multiple inputs and outputs, by Banker et al. (1984) [18]. By sorting out the existing studies, it is found that China's research on ecological efficiency, especially the ecological efficiency of the Yangtze River Delta, mainly focuses on: the comprehensive influencing factors of ecological efficiency $[19,20]$; the interaction between economic development, industrial agglomeration, and the ecological environment [21,22]; or the relationship between the population, the economy, and the ecological environment [23,24]. However, there are few studies on the coordination between population agglomeration and ecological efficiency. Research methods, such as the supply-demand balance method [25], the ecological footprint method [26], and the imbalance index [27] are mainly used to study the pressure of regional population activities on the ecological environment.

Population agglomeration and the ecological environment are mutually restricted, coupled, and symbiotic [28]. On the one hand, population agglomeration imposes a stress effect on the ecological environment. Excessive population concentration increases the consumption of resources and the emission of pollutants, increases the carrying capacity of the ecological environment, and highlights the negative environmental effects. On the other hand, with the increase in the urban population, the previous modes of production and lifestyle have changed, which may further enhance the scale effect on the environment. The urban ecological environment is not only the operation carrier of urbanization development, but also the basic space for urban population production and life. It can not only provide the necessary resources for consumption but can also effectively carry and offset the negative effects brought on by population agglomeration, to a certain extent. At the same time, the ecological environment exerts a certain constraint effect on population agglomeration. The deterioration of the ecology will lead to a reduction in the quality of the living environment and will even reduce the level of urbanization development by excluding the population.

In the research on urbanization and the ecological environment, many studies focus on the economy and the environment, while few concentrate on the impact of, or the interaction between, population agglomerations and urban ecological environments. From the basis of this perspective, this research uses the coupling coordination model $[29,30]$ to explore the coupling coordination interaction [31] of population agglomerations and urban ecological environments, so as to enrich the research system on urban ecological environments. 


\section{Materials and Methods}

\subsection{Data Envelopment Analysis}

\subsubsection{Research Method}

Data envelopment analysis was proposed by Chames, Cooper, and Rhode in 1978 [17] and was aimed at evaluating the relative effectiveness of the decision unit in the "multiinput, multi-output" mode. The basic idea of ecological efficiency is to minimize resource consumption and environmental pollution while maximizing value, which means attaining the maximum economic value with the least resource input and minimal environment costs. This is consistent with the requirements of the DEA method for input and output indicators.

\subsubsection{Data Indicators and Sources}

Ecological efficiency is a comprehensive manifestation of environmental, resource, and economic elements. In DEA specific applications, the income indexes are generally construed as an output indicator. The larger the value of such indicators, the better the cost class indicator as an input indicator, and the smaller the value, the better. However, in the actual situation with population agglomeration and economic development, there are not only desirable indicators, but also nondesirable indicators. Therefore, this paper takes desirable output (GDP) and undesirable output (environmental pollution) as output indicators, and resource consumption as an input indicator. The indicators in detail are shown in Table 1.

Table 1. Input and output indicators.

\begin{tabular}{ccc}
\hline Indicator & Category & Indicators in Detail \\
\hline Input indicators & & Urban green space area \\
& & Total water consumption \\
& Total power consumption \\
& Total gas supply \\
Output indicators & Total LPG supply \\
& Desirable output & Regional gross domestic product (GDP) \\
& Undesirable output & Industrial wastewater discharge \\
& Sulfur dioxide emissions \\
& & Smoke (powder) dust emissions \\
\hline
\end{tabular}

The selected input indicators reflect the resource consumption, including the urban green space area, the total power consumption of the whole society, the total water consumption, the total gas supply, and the total LPG supply. Output is divided into desirable output and undesirable output. The preferred output index is the regional gross domestic product (GDP), and the nondesirable output indicators are environmental pollution, including industrial wastewater discharge, sulfur dioxide emissions, and smoke (powder) dust emissions.

The data of the indicators in detail were acquired from the China Urban Statistical Yearbook, the China Urban Construction Statistical Yearbook, the Yangtze River and Pearl River Delta, Hong Kong, Macao, and Taiwan Statistical Yearbooks, the Zhejiang Statistical Yearbook, the Jiangsu Statistical Yearbook, and the Anhui Statistical Yearbook and the statistical yearbooks and statistical bulletins of 26 cities in the Yangtze River Delta urban agglomeration over the years.

\subsection{Coupling Coordination Model}

\subsubsection{Model Introduction}

The term "coupling" originates from a concept in physics and refers to the phenomenon where two or more systems or motion forms affect each other through various interactions. The "coupling degree" refers to the degree of interaction between individuals, which is used to measure the relationship between the elements of the system. The "coordination degree" refers to the degree of benign coupling in the interaction. It is the 
relationship between the coordination and the virtuous circle among the elements of the system. The quality of the coordination can represent whether the elements promote each other at a high level or restrict each other at a low level. On the basis of the relevant research results of other scholars [29,30], a coupling coordination degree measurement model between population agglomeration and ecological efficiency was constructed, and the calculation formula is as follows:

$$
\begin{gathered}
C=\left\{\frac{P \times E}{\left[\frac{P+E}{2}\right]^{2}}\right\}^{\frac{1}{2}} \\
T=\alpha P+\beta E \\
D=\sqrt{C \times T}
\end{gathered}
$$

where $C$ is the coupling degree of the population agglomeration and ecological efficiency; $\mathrm{T}$ is the comprehensive evaluation index; $\mathrm{D}$ is the coupling coordination degree; $\mathrm{P}$ and $\mathrm{E}$ represent the degree of population agglomeration and ecological efficiency, respectively; and $\alpha$ and $\beta$ are the undetermined weight. This paper believes that urbanization development and ecological environmental protection are equally important, so $\alpha$ and $\beta$ both take the value of 0.5 .

\subsubsection{Grade Classification}

For the calculation of the relevant results, this paper used SPSS software to analyze the results in clusters and classify the coupling degrees and the coordination degrees. The

\begin{tabular}{|c|c|c|}
\hline Range & Category & Features \\
\hline$[0,0.4]$ & Primary coupling & $\begin{array}{l}\text { The degree of population agglomeration is low, the } \\
\text { environmental carrying capacity is strong, and the } \\
\text { damage of population agglomeration to the ecological } \\
\text { environment is small. The ecological environment can } \\
\text { carry and offset the impact of population agglomeration. }\end{array}$ \\
\hline$(0.4,0.6]$ & Low coupling & $\begin{array}{l}\text { The rapid development of the city urgently needs capital, } \\
\text { labor, and other resources as input. At the same time, it } \\
\text { produces a large amount of environmental pollution, and } \\
\text { the carrying capacity of the ecological environment has } \\
\text { decreased and can no longer fully absorb the negative } \\
\text { impact of population agglomeration. }\end{array}$ \\
\hline$(0.6,0.8]$ & Medium coupling & $\begin{array}{l}\text { With the continuous improvement in the urbanization } \\
\text { level, and because of the damage to the ecological } \\
\text { environment caused by the excessive pursuit of economic } \\
\text { and social development in the early stage of development, } \\
\text { urban managers need to invest more funds and energy to } \\
\text { make up for it, and the benign coupling development } \\
\text { between population and ecology has begun. }\end{array}$ \\
\hline$(0.8,1]$ & Advanced coupling & $\begin{array}{l}\text { The development level of urbanization has been rapidly } \\
\text { improved not only in quantity, but also in quality. } \\
\text { Population agglomeration and ecological environment } \\
\text { construction promote and complement each other. }\end{array}$ \\
\hline
\end{tabular}
results are shown in Tables 2 and 3.

Table 2. Division of coupling degrees between population agglomeration and ecological efficiency. 
Table 3. Division of coordination degrees between population agglomeration and ecological efficiency.

\begin{tabular}{|c|c|c|}
\hline Range & Category & Features \\
\hline$[0,0.5]$ & $\begin{array}{c}\text { Low } \\
\text { coordination }\end{array}$ & $\begin{array}{l}\text { Disorderly population agglomeration has caused serious } \\
\text { damage to the ecological environment, and the ecological } \\
\text { space has been seriously squeezed, resulting in } \\
\text { environmental pollution and destruction, and the ecological } \\
\text { problems have become increasingly prominent. }\end{array}$ \\
\hline$(0.5,0.7]$ & Medium coordination & $\begin{array}{l}\text { Urban managers have begun to formulate plans to guide } \\
\text { the rational distribution of the urban population, and have } \\
\text { begun to formulate relevant environmental governance } \\
\text { policies. The ecological problems caused by population } \\
\text { agglomeration have begun to ease. }\end{array}$ \\
\hline$(0.7,0.9]$ & High coordination & $\begin{array}{l}\text { Urban planning and policies have played a steady role, the } \\
\text { ecological impact caused by rapid population } \\
\text { agglomeration has been gradually reduced, and the city has } \\
\text { begun to enter the stage of green development. }\end{array}$ \\
\hline$(0.9,1]$ & Ultimate coordination & $\begin{array}{l}\text { There is a positive relationship between population } \\
\text { agglomeration and ecological efficiency. Population } \\
\text { agglomeration will not cause damage to the ecological } \\
\text { environment. On the contrary, the expansion of the } \\
\text { population scale and the improvement in the agglomeration } \\
\text { degree has an economic agglomeration effect, and improves } \\
\text { the overall ecological efficiency of the city. }\end{array}$ \\
\hline
\end{tabular}

\section{Results}

\subsection{Basic Population Situation}

According to the statistical yearbooks of each city, by the end of 2018, the 26 city administrative regions of the city group in the Yangtze River Delta area were about 214,001 square kilometers, with a registered residence population totaling 132,302,400 people, and the population density was about 780.43 people $/ \mathrm{km}^{2}$ The registered residence population in Shanghai was largest among the 26 cities, with about 14,475,700 people, and the registered residence population in Zhoushan was smallest, with about 969,000 people. The maximum population density was from Shanghai, at about 3823 people $/ \mathrm{km}^{2}$, and the minimum population density was from Chizhou, at about 193 people $/ \mathrm{km}^{2}$; The highest urbanization rate was from Shanghai, which was about $87.60 \%$, and the lowest urbanization rate was from Anqing, with about $49.2 \%$. See Table 4 for details.

Excluding the impact of severe economic fluctuations on society and considering the special situation of the data of individual provinces and years, this paper selected the relevant data from 2008, 2010, 2013, 2015, and 2018 for research (the same below). In selecting population density data to analyze the population distribution of urban agglomeration in the Yangtze River Delta (Table 5), we found that Shanghai had the largest population density, about 3689.8 people $/ \mathrm{km}^{2}$, and Chizhou had the smallest population density, about 193.548 people $/ \mathrm{km}^{2}$. On this basis, ArcGIS 10.3 software was used to draw the population density map for five years, from 2008 to 2018 (Figure 1), to explore the spatial evolution characteristics of the population densities of the urban agglomeration in the Yangtze River Delta.

As can be seen from Figure 1, the population of the Yangtze River Delta urban agglomeration from 2008-2018 was mainly concentrated in the middle eastern region. Except for Nantong, Yancheng, and Maanshan, most of the other cities show upward trends for their population densities, mainly Shanghai, Hangzhou, Nanjing, Wuxi, and Changzhou. Over the years, the average population density of Shanghai was 3689.8 people $/ \mathrm{km}^{2}$, much higher than that of Wuxi, at 1165.2 people $/ \mathrm{km}^{2}$, of Nanjing, at 1136.568 people $/ \mathrm{km}^{2}$, and of Changzhou, at 1019.822 people $/ \mathrm{km}^{2}$. This indicates that there is a large gap between the population scales and agglomeration degrees of other levels of cities in the Yangtze River Delta urban agglomeration. Of the first-level cities, the population distribution between 
regions is unbalanced, the cascade difference in the population densities is large, and the spatial characteristics of the population agglomeration are obvious. The population offset growth of urban agglomeration in the Yangtze River Delta shows an upward trend, and gradually forms a population spatial circle system structure, with Shanghai as the center, and Nanjing and Hangzhou as the subcenters. However, the imbalance index of the population spatial distribution shows an upward trend on the whole.

Table 4. Populations of 26 cities in the Yangtze River Delta in 2018.

\begin{tabular}{|c|c|c|c|c|c|c|}
\hline City & Province & $\begin{array}{c}\text { Administrative } \\
\text { Area }\left(\mathrm{km}^{2}\right)\end{array}$ & $\begin{array}{c}\text { Permanent } \\
\text { Resident } \\
\text { Population } \\
(10,000 \text { Persons })\end{array}$ & $\begin{array}{c}\text { Registered } \\
\text { Residence } \\
\text { Population } \\
(10,000 \text { Persons) }\end{array}$ & $\begin{array}{c}\text { Population } \\
\text { Density } \\
\text { (Person/Square } \\
\text { Kilometre) }\end{array}$ & $\begin{array}{c}\text { Urbanization } \\
\text { Rate (\%) }\end{array}$ \\
\hline Shanghai & Shanghai & 6341 & 2423.78 & 1447.57 & 3823 & 87.60 \\
\hline Nanjing & Jiangsu Province & 6587 & 843.62 & 696.94 & 1281 & 82.50 \\
\hline Wuxi & Jiangsu Province & 4627 & 657.45 & 497.21 & 1421 & 76.28 \\
\hline Changzhou & Jiangsu Province & 4372 & 472.9 & 382.2 & 1082 & 72.50 \\
\hline Suzhou & Jiangsu Province & 8657 & 1072.17 & 703.55 & 813 & 76.05 \\
\hline Nantong & Jiangsu Province & 10,549 & 731 & 762.52 & 693 & 67.10 \\
\hline Yancheng & Jiangsu Province & 16,931 & 720 & 824.7 & 425 & 64.03 \\
\hline Yangzhou & Jiangsu Province & 6591 & 453.1 & 458.34 & 687 & 66.05 \\
\hline Zhenjiang & Jiangsu Province & 3840 & 319.64 & 270.78 & 832 & 71.20 \\
\hline Taizhou & Jiangsu Province & 5787 & 463.57 & 503.39 & 801 & 66.00 \\
\hline Hangzhou & Zhejiang Province & 16,853 & 980.6 & 774.1 & 582 & 77.40 \\
\hline Ningbo & Zhejiang Province & 9816 & 820.2 & 603 & 614 & 72.90 \\
\hline Jiaxing & Zhejiang Province & 4223 & 472.6 & 360.44 & 854 & 66.00 \\
\hline Huzhou & Zhejiang Province & 5820 & 302.7 & 367.06 & 459 & 63.50 \\
\hline Shaoxing & Zhejiang Province & 8279 & 503.5 & 447.21 & 535.31 & 66.60 \\
\hline Jinhua & Zhejiang Province & 10,942 & 560.4 & 488.97 & 447 & 67.70 \\
\hline Zhoushan & Zhejiang Province & 1459 & 117.3 & 96.9 & 297.1 & 68.10 \\
\hline Taizhou & Zhejiang Province & 10,050 & 613.9 & 605.4 & 602 & 63.00 \\
\hline Hefei & Zhejiang Province & 11,445 & 808.7 & 727.96 & 651 & 74.97 \\
\hline Wuhu & Zhejiang Province & 6026 & 374.8 & 388.85 & 641 & 66.54 \\
\hline Maanshan & Zhejiang Province & 4049 & 233.7 & 229.11 & 566 & 68.20 \\
\hline Tongling & Zhejiang Province & 2991 & 162.9 & 170.8 & 617.23 & 56.00 \\
\hline Anqing & Zhejiang Province & 13,538 & 469.1 & 528.44 & 389 & 49.20 \\
\hline Chuzhou & Zhejiang Province & 13,516 & 411.4 & 453.7 & 332.6 & 53.40 \\
\hline Chizhou & Zhejiang Province & 8399 & 147.4 & 162.2 & 193 & 54.10 \\
\hline Xuancheng & Zhejiang Province & 12,313 & 264.8 & 278.9 & 228 & 55.20 \\
\hline
\end{tabular}

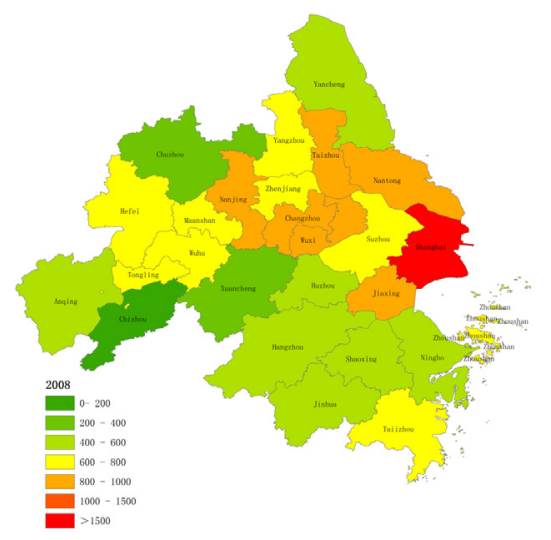

(a)

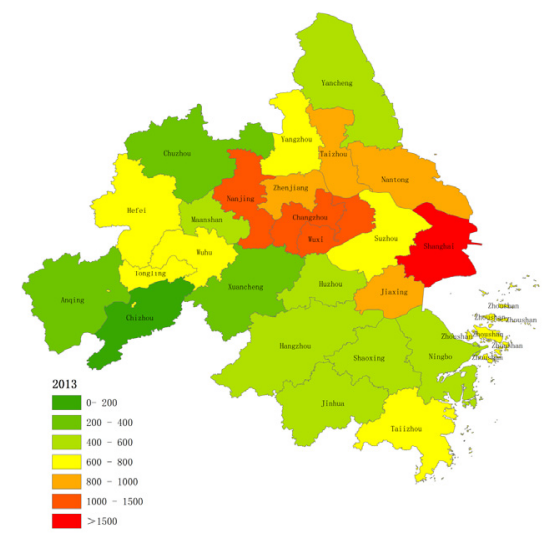

(b)

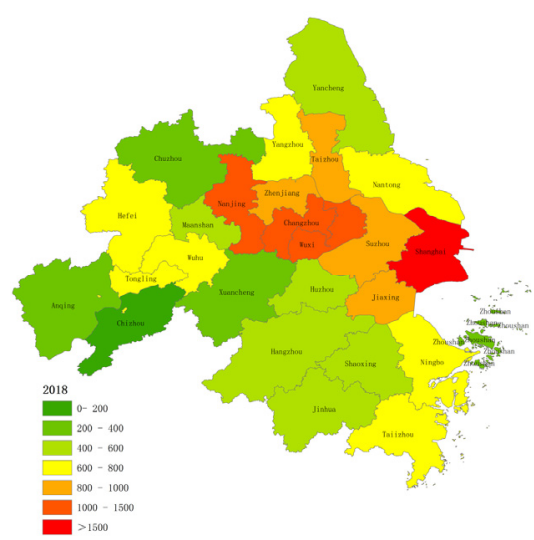

(c)

Figure 1. (a) First panel shows the population densities in the Yangtze River Delta urban group in 2008; (b) Second panel shows the population densities in the Yangtze River Delta urban group in 2013; (c) Third panel shows the population densities in the Yangtze River Delta urban group in 2018. 
Table 5. Population densities of 26 cities in Yangtze River Delta urban agglomeration, from 2008 to 2018 (person $\left./ \mathrm{km}^{2}\right)$.

\begin{tabular}{cccccc}
\hline City & Year 2008 & Year 2010 & Year 2013 & Year 2015 & Year 2018 \\
\hline Shanghai & 3376 & 3632 & 3809 & 3809 & 3823 \\
Nanjing & 948.74 & 960.1 & 1243 & 1250 & 1281 \\
Wuxi & 970 & 1008 & 1020 & 1407 & 1421 \\
Changzhou & 818.11 & 1051 & 1073 & 1075 & 1082 \\
Suzhou & 742 & 751 & 770 & 770 & 813 \\
Nantong & 954.53 & 954 & 912 & 727.08 & 693 \\
Yancheng & 478 & 481 & 486 & 427 & 425 \\
Yangzhou & 693.08 & 697 & 643 & 690 & 687 \\
Zhenjiang & 698.65 & 704 & 823 & 827 & 832 \\
Taizhou & 864.04 & 782.04 & 877.48 & 802 & 801 \\
Hangzhou & 408.32 & 415.23 & 426 & 436.25 & 582 \\
Ningbo & 579 & 585 & 590 & 598 & 614 \\
Jiaxing & 864 & 873 & 884 & 893 & 854 \\
Huzhou & 444.31 & 446.85 & 450.7 & 453.61 & 459 \\
Shaoxing & 529.38 & 530.15 & 533.47 & 535.09 & 535.31 \\
Jinhua & 421.73 & 426.51 & 432.6 & 436.85 & 447 \\
Zhoushan & 672.01 & 672.01 & 668.8 & 666.67 & 672 \\
Taizhou & 609.99 & 619.63 & 631.22 & 634.36 & 602 \\
Hefei & 690.69 & 702.36 & 621.67 & 627.25 & 651 \\
Wuhu & 695.78 & 691.89 & 642.18 & 638.9 & 641 \\
Maanshan & 759.59 & 765.72 & 564.09 & 565.57 & 566 \\
Tongling & 663.88 & 664.96 & 618.07 & 616.15 & 617.23 \\
Anqing & 400.76 & 383 & 387 & 403.84 & 389 \\
Chuzhou & 330.82 & 333.36 & 332.53 & 332.2 & 332.6 \\
Chizhou & 192.15 & 193.98 & 195.73 & 192.88 & 193 \\
Xuancheng & 224.58 & 225.89 & 225.01 & 227.4 & 228 \\
\hline
\end{tabular}

\subsection{DEA Results Analysis}

Data envelopment analysis was proposed by Chames, Cooper, and Rhode in 1978, and was aimed at evaluating the relative effectiveness of the decision unit in the "multiinput, multi-output" mode. The basic idea of ecological efficiency is to minimize resource consumption and environmental pollution while maximizing value, which means attaining the maximum economic value with the least resource input and minimal environment costs. This is consistent with the requirements of the DEA method for input and output indicators.

DEA is the most effective nonparametric research method for evaluating efficiency. On the basis of the DEA model, combined with the input-output index data, this paper used the software, DEAP 2.1, to calculate the ecological efficiencies of 26 cities in the Yangtze River Delta urban agglomeration from 2008 to 2018, as shown in Table 6.

It can be seen from Table 3 that, from 2008 to 2018, the overall ecological efficiencies of the 26 cities in the Yangtze River Delta urban agglomeration changed greatly, and there were obvious differences among different provinces and cities.

From the perspective of the time series, the overall ecological efficiencies of the 26 cities showed an upward trend from 2008 to 2018, especially in Shanghai, Nanjing, Wuxi, and other cities. Taking Shanghai as an example, from the relevant input-output data from 2008 to 2018 (Table 7), it can be seen that, while GDP increases, the emissions of industrial wastewater, sulfur dioxide, and smoke (powder) dust are gradually decreasing, and the area of urban green space is greatly increasing. This shows that cities in the Yangtze River Delta are beginning to change, or have changed, from the extensive economic growth mode to the intensive and high-quality development path. However, on the whole, the ecological efficiencies of some cities are still not high, and the mode of economic growth is more dependent on the high input of resources and the high emissions of pollution, which seriously restrict improvement in the regional ecological efficiency. 
Table 6. Calculation results of the ecological efficiencies of 26 cities in the Yangtze River Delta urban agglomeration from 2008 to 2018.

\begin{tabular}{ccccccc}
\hline City & $\mathbf{2 0 0 8}$ & $\mathbf{2 0 1 0}$ & $\mathbf{2 0 1 3}$ & $\mathbf{2 0 1 5}$ & $\mathbf{2 0 1 8}$ & $\begin{array}{c}\text { Average } \\
\text { Values }\end{array}$ \\
\hline Shanghai & 0.399 & 0.216 & 0.320 & 0.335 & 0.827 & 0.419 \\
Nanjing & 0.299 & 0.220 & 0.355 & 0.429 & 0.893 & 0.439 \\
Wuxi & 0.527 & 1.000 & 0.819 & 0.806 & 0.881 & 0.807 \\
Changzhou & 0.811 & 0.946 & 1.000 & 1.000 & 0.847 & 0.921 \\
Suzhou & 0.762 & 1.000 & 0.874 & 0.980 & 0.986 & 0.920 \\
Nantong & 1.000 & 1.000 & 1.000 & 1.000 & 1.000 & 1.000 \\
Yancheng & 1.000 & 1.000 & 1.000 & 1.000 & 1.000 & 1.000 \\
Yangzhou & 1.000 & 0.905 & 0.619 & 0.871 & 1.000 & 0.879 \\
Zhenjiang & 0.608 & 0.476 & 0.772 & 0.829 & 0.782 & 0.693 \\
Taizhou & 1.000 & 1.000 & 1.000 & 1.000 & 1.000 & 1.000 \\
Hangzhou & 0.737 & 0.658 & 0.436 & 0.464 & 0.777 & 0.614 \\
Ningbo & 0.712 & 0.680 & 0.865 & 0.661 & 0.875 & 0.759 \\
Jiaxing & 1.000 & 1.000 & 1.000 & 1.000 & 1.000 & 1.000 \\
Huzhou & 0.956 & 0.770 & 1.000 & 1.000 & 1.000 & 0.945 \\
Shaoxing & 1.000 & 1.000 & 0.985 & 1.000 & 1.000 & 0.997 \\
Jinhua & 1.000 & 1.000 & 1.000 & 1.000 & 1.000 & 1.000 \\
Zhoushan & 0.610 & 0.895 & 0.501 & 0.613 & 1.000 & 0.724 \\
Taihzou & 1.000 & 1.000 & 1.000 & 1.000 & 0.980 & 0.996 \\
Hefei & 0.400 & 0.420 & 0.765 & 0.777 & 1.000 & 0.672 \\
Wuhu & 0.585 & 0.460 & 0.622 & 0.704 & 0.852 & 0.645 \\
Maanshan & 1.000 & 1.000 & 1.000 & 1.000 & 1.000 & 1.000 \\
Tongling & 0.671 & 0.500 & 1.000 & 1.000 & 1.000 & 0.834 \\
Anqing & 0.661 & 0.608 & 0.514 & 0.737 & 1.000 & 0.704 \\
Chuzhou & 0.998 & 1.000 & 1.000 & 1.000 & 1.000 & 1.000 \\
Chizhou & 1.000 & 1.000 & 1.000 & 1.000 & 1.000 & 1.000 \\
Xuancheng & 1.000 & 1.000 & 1.000 & 1.000 & 1.000 & 1.000 \\
Average value & 0.798 & 0.798 & 0.825 & 0.854 & 0.950 & 0.845 \\
\hline
\end{tabular}

Table 7. Input-output indicator data for Shanghai from 2008 to 2018.

\begin{tabular}{|c|c|c|c|c|c|}
\hline Indicator & 2008 & 2010 & 2013 & 2015 & 2018 \\
\hline GDP (RMB 100 million) & $14,069.87$ & $17,436.85$ & $22,264.06$ & $25,659.18$ & $32,679.87$ \\
\hline $\begin{array}{l}\text { Industrial wastewater discharge } \\
\qquad(10,000 \text { tons })\end{array}$ & 44,120 & 36,696 & 45,400 & 46,900 & 29,144 \\
\hline Sulfur dioxide emissions (ton) & 298,000 & 221,476 & 172,900 & 104,900 & 9100 \\
\hline $\begin{array}{l}\text { Industrial smoke (powder) dust } \\
\text { emissions (ton) }\end{array}$ & 40,629 & 41,793 & 67,200 & 11,140 & 16,163 \\
\hline Urban green space area (HA) & 34,256 & 120,148 & 124,295 & 127,332 & 139,427 \\
\hline Total water supply (10,000 tons) & 349,481 & 308,999 & 319,072 & 304,440 & 243,514 \\
\hline $\begin{array}{l}\text { Power consumption of the whole } \\
\text { society }(10,000 \mathrm{KWH})\end{array}$ & $11,382,200$ & $12,958,700$ & $14,106,000$ & $14,055,500$ & $15,666,595$ \\
\hline Total gas supply $\left(10,000 \mathrm{~m}^{3}\right)$ & 497,742 & 592,199 & 750,231 & 740,085 & 892,863 \\
\hline Total LPG supply (ton) & 482,268 & 398,427 & 397,314 & 424,112 & 313,578 \\
\hline
\end{tabular}

From the perspective of the spatial dimension, there are also obvious differences in ecological efficiencies among cities. According to the GDPs and the population density indicators, 26 cities are divided into two categories: high GDP and high population density, and low GDP and low population density. We selected any one city from each category, which were Shanghai and Xuancheng, for comparison. Taking 2018 as an example, the total GDP of Shanghai was CNY 3267.987 billion, and the population density was 3823 people $/ \mathrm{km}^{2}$, while the total GDP of Xuancheng was CNY 131.72 billion, and the population density was 
228 (people $/ \mathrm{km}^{2}$ ). The ecological efficiency of the former was 0.827 , and that of the latter was 1.000 .

Usually, in the process of pursuing development, in order to achieve economic growth, cities adopt a more extensive economic development mode in the early and middle stages of economic construction, so as to increase the corresponding resource consumption, thereby producing more environmental pollution. At the same time, rapid population agglomeration is also one of the fundamental reasons for the rapid increase in resource demand and pollution emissions. The increase in the population density further increases resource consumption and environmental pollution, resulting in the overall low ecological efficiency. Judging only from the overall results of the ecological efficiency measurements, the ecological efficiencies of cities with high GDPs and high population densities, such as Shanghai, are low, and those of cities with low GDPs and low population densities, such as Xuancheng, are high. In view of the above data, we established a coupling coordination degree model to calculate the coordination between the population agglomeration degree and the ecological efficiency, so as to explore whether the ecological efficiency was low due to excessive population agglomeration in the Yangtze River Delta urban agglomeration.

\subsection{Coupling Coordination Degree Results Analysis}

\subsubsection{Measurement Results}

Using the coupled coordination model for measurement, we obtained the coupling coordination degree values and the corresponding levels between the population agglomerations and the ecological efficiencies of cities in the Yangtze River Delta urban agglomeration, as shown in Table 8.

According to the calculation results, the coupling coordination degrees of most cities range from 0.5 to 0.9 , which is at the medium and high coordination levels. In 2018, the maximum coupling coordination degree was from Shanghai, at 0.954 , an extremely coordinated level. The coupling coordination degrees of Xuancheng and Chizhou were low, at 0.494 and 0.474 , respectively.

From the perspective of the time series, the overall coupling coordination degree shows a trend of "decrease-increase-increase-increase". The downward trend in the first stage shows that relevant urban managers unilaterally pursued an improvement in the urbanization rate in response to the trends of the times and to improve performance. Although the numbers of the urban population increase rapidly, their distribution structure and overall quality are still relatively extensive, and population agglomeration produces a series of ecological problems, which made the coupling and coordination stage between them stagnate, and even regress to the previous stage. The continuous improvement in the coupling and coordination degrees in the second, third and fourth stages shows that, after the extensive population and urban development in the first and middle stages, urban managers were aware of the damage caused by one-sided urbanization to the ecological space and took effective countermeasures. The city changed the existing structure and development mode and gradually developed in the direction of optimization, coordination, and the virtuous circle.

From the perspective of the spatial dimension, the coupling degrees and coordination levels of the population agglomerations and ecological efficiencies of eastern cities in the Yangtze River Delta urban agglomeration are relatively high, showing a trend of agglomeration. Specifically, the central cities, such as Shanghai and Nanjing, are in the high/extremely high coupling coordination stage, and the marginal cities, such as Chizhou and Xuancheng, are mostly in the low/medium coupling coordination stage. However, because of the spatial change trends in the coupling coordination degree over the years, the agglomeration area is gradually expanding, indicating that the overall population agglomeration and ecological efficiency of urban agglomeration in the Yangtze River Delta are approaching the benign coupling coordination. 
Table 8. Values and grades of coupling coordination degrees of cities in Yangtze River Delta urban agglomeration.

\begin{tabular}{|c|c|c|c|c|c|c|c|c|c|c|c|c|c|}
\hline City & Year & 2008 & 2010 & 2013 & 2015 & 2018 & City & Year & 2008 & 2010 & 2013 & 2015 & 2018 \\
\hline \multirow{3}{*}{ Shanghai } & C & 0.903 & 0.764 & 0.857 & 0.867 & 0.996 & \multirow{3}{*}{ Huzhou } & C & 0.652 & 0.689 & 0.615 & 0.617 & 0.619 \\
\hline & $\mathrm{D}$ & 0.795 & 0.682 & 0.752 & 0.761 & 0.954 & & $\mathrm{D}$ & 0.596 & 0.555 & 0.587 & 0.587 & 0.589 \\
\hline & Degree & $\mathrm{H} / \mathrm{H}$ & $\mathrm{M} / \mathrm{M}$ & $\mathrm{H} / \mathrm{H}$ & $\mathrm{H} / \mathrm{H}$ & $\mathrm{H} / \mathrm{U}$ & & Degree & $\mathrm{M} / \mathrm{M}$ & $\mathrm{M} / \mathrm{M}$ & $\mathrm{M} / \mathrm{M}$ & $\mathrm{M} / \mathrm{M}$ & $\mathrm{M} / \mathrm{M}$ \\
\hline \multirow{3}{*}{ Nanjing } & C & 0.995 & 0.996 & 0.991 & 0.991 & 0.891 & \multirow{3}{*}{ Shaoxing } & C & 0.685 & 0.667 & 0.660 & 0.657 & 0.656 \\
\hline & $\mathrm{D}$ & 0.538 & 0.491 & 0.583 & 0.613 & 0.740 & & $\mathrm{D}$ & 0.629 & 0.618 & 0.609 & 0.612 & 0.612 \\
\hline & Degree & $\mathrm{H} / \mathrm{M}$ & $\mathrm{H} / \mathrm{L}$ & $\mathrm{H} / \mathrm{M}$ & $\mathrm{H} / \mathrm{M}$ & $\mathrm{H} / \mathrm{H}$ & & Degree & $\mathrm{M} / \mathrm{M}$ & $\mathrm{M} / \mathrm{M}$ & $\mathrm{M} / \mathrm{M}$ & $\mathrm{M} / \mathrm{M}$ & $\mathrm{M} / \mathrm{M}$ \\
\hline \multirow{3}{*}{ Wuxi } & $\mathrm{C}$ & 0.956 & 0.825 & 0.862 & 0.928 & 0.914 & \multirow{3}{*}{ Jinhua } & $\mathrm{C}$ & 0.628 & 0.613 & 0.605 & 0.608 & 0.612 \\
\hline & $\mathrm{D}$ & 0.624 & 0.726 & 0.684 & 0.739 & 0.756 & & $\mathrm{D}$ & 0.595 & 0.585 & 0.581 & 0.582 & 0.585 \\
\hline & Degree & $\mathrm{H} / \mathrm{M}$ & $\mathrm{H} / \mathrm{H}$ & $\mathrm{H} / \mathrm{M}$ & $\mathrm{H} / \mathrm{H}$ & $\mathrm{H} / \mathrm{H}$ & & Degree & $\mathrm{M} / \mathrm{M}$ & $\mathrm{M} / \mathrm{M}$ & $\mathrm{M} / \mathrm{M}$ & $\mathrm{M} / \mathrm{M}$ & $\mathrm{M} / \mathrm{M}$ \\
\hline \multirow{3}{*}{ Changzhou } & $\mathrm{C}$ & 0.842 & 0.847 & 0.828 & 0.829 & 0.867 & \multirow{3}{*}{ Zhoushan } & C & 0.861 & 0.754 & 0.877 & 0.831 & 0.517 \\
\hline & $\mathrm{D}$ & 0.666 & 0.723 & 0.729 & 0.729 & 0.730 & & $\mathrm{D}$ & 0.590 & 0.638 & 0.545 & 0.572 & 0.528 \\
\hline & Degree & $\mathrm{H} / \mathrm{M}$ & $\mathrm{H} / \mathrm{H}$ & $\mathrm{H} / \mathrm{H}$ & $\mathrm{H} / \mathrm{H}$ & $\mathrm{H} / \mathrm{H}$ & & Degree & $\mathrm{H} / \mathrm{M}$ & $\mathrm{M} / \mathrm{M}$ & $\mathrm{H} / \mathrm{M}$ & $\mathrm{H} / \mathrm{M}$ & $\mathrm{L} / \mathrm{M}$ \\
\hline \multirow{3}{*}{ Suzhou } & C & 0.834 & 0.754 & 0.781 & 0.753 & 0.764 & \multirow{3}{*}{ Taizhou } & $\mathrm{C}$ & 0.720 & 0.706 & 0.698 & 0.700 & 0.691 \\
\hline & D & 0.640 & 0.674 & 0.648 & 0.667 & 0.677 & & $\mathrm{D}$ & 0.652 & 0.643 & 0.638 & 0.639 & 0.627 \\
\hline & Degree & $\mathrm{H} / \mathrm{M}$ & $\mathrm{M} / \mathrm{M}$ & $\mathrm{M} / \mathrm{M}$ & $\mathrm{M} / \mathrm{M}$ & $\mathrm{M} / \mathrm{M}$ & & Degree & $\mathrm{M} / \mathrm{M}$ & $\mathrm{M} / \mathrm{M}$ & $\mathrm{M} / \mathrm{M}$ & $\mathrm{M} / \mathrm{M}$ & $\mathrm{M} / \mathrm{M}$ \\
\hline \multirow{3}{*}{ Nantong } & C & 0.829 & 0.812 & 0.790 & 0.734 & 0.721 & \multirow{3}{*}{ Hefei } & $\mathrm{C}$ & 0.946 & 0.929 & 0.761 & 0.760 & 0.705 \\
\hline & $\mathrm{D}$ & 0.729 & 0.716 & 0.695 & 0.661 & 0.653 & & $\mathrm{D}$ & 0.535 & 0.534 & 0.594 & 0.598 & 0.642 \\
\hline & Degree & $\mathrm{H} / \mathrm{H}$ & $\mathrm{H} / \mathrm{H}$ & $\mathrm{M} / \mathrm{M}$ & $\mathrm{M} / \mathrm{M}$ & $\mathrm{M} / \mathrm{M}$ & & Degree & $\mathrm{H} / \mathrm{M}$ & $\mathrm{H} / \mathrm{M}$ & $\mathrm{M} / \mathrm{M}$ & $\mathrm{M} / \mathrm{M}$ & $\mathrm{M} / \mathrm{M}$ \\
\hline \multirow{3}{*}{ Yancheng } & $\mathrm{C}$ & 0.659 & 0.643 & 0.634 & 0.602 & 0.600 & \multirow{3}{*}{ Wuhu } & $\mathrm{C}$ & 0.878 & 0.910 & 0.819 & 0.788 & 0.741 \\
\hline & $\mathrm{D}$ & 0.613 & 0.603 & 0.598 & 0.579 & 0.577 & & $\mathrm{D}$ & 0.589 & 0.544 & 0.569 & 0.586 & 0.615 \\
\hline & Degree & $\mathrm{M} / \mathrm{M}$ & $\mathrm{M} / \mathrm{M}$ & $\mathrm{M} / \mathrm{M}$ & $\mathrm{M} / \mathrm{M}$ & $\mathrm{M} / \mathrm{M}$ & & Degree & $\mathrm{H} / \mathrm{M}$ & $\mathrm{H} / \mathrm{M}$ & $\mathrm{H} / \mathrm{M}$ & $\mathrm{M} / \mathrm{M}$ & $\mathrm{M} / \mathrm{M}$ \\
\hline \multirow{3}{*}{ Yangzhou } & $\mathrm{C}$ & 0.752 & 0.760 & 0.821 & 0.755 & 0.719 & \multirow{3}{*}{ Maanshan } & C & 0.774 & 0.758 & 0.670 & 0.671 & 0.670 \\
\hline & $\mathrm{D}$ & 0.673 & 0.646 & 0.569 & 0.630 & 0.651 & & D & 0.689 & 0.678 & 0.620 & 0.621 & 0.620 \\
\hline & Degree & $\mathrm{M} / \mathrm{M}$ & $\mathrm{M} / \mathrm{M}$ & $\mathrm{H} / \mathrm{M}$ & $\mathrm{M} / \mathrm{M}$ & $\mathrm{M} / \mathrm{M}$ & & Degree & $\mathrm{M} / \mathrm{M}$ & $\mathrm{M} / \mathrm{M}$ & $\mathrm{M} / \mathrm{M}$ & $\mathrm{M} / \mathrm{M}$ & $\mathrm{M} / \mathrm{M}$ \\
\hline \multirow{3}{*}{ Zhenjiang } & $\mathrm{C}$ & 0.871 & 0.907 & 0.827 & 0.811 & 0.825 & \multirow{3}{*}{ Tongling } & C & 0.837 & 0.886 & 0.693 & 0.692 & 0.692 \\
\hline & $\mathrm{D}$ & 0.596 & 0.551 & 0.639 & 0.651 & 0.642 & & D & 0.603 & 0.550 & 0.635 & 0.634 & 0.634 \\
\hline & Degree & $\mathrm{H} / \mathrm{M}$ & $\mathrm{H} / \mathrm{M}$ & $\mathrm{H} / \mathrm{M}$ & $\mathrm{H} / \mathrm{M}$ & $\mathrm{H} / \mathrm{M}$ & & Degree & $\mathrm{H} / \mathrm{M}$ & $\mathrm{H} / \mathrm{M}$ & $\mathrm{M} / \mathrm{M}$ & $\mathrm{M} / \mathrm{M}$ & $\mathrm{M} / \mathrm{M}$ \\
\hline \multirow{3}{*}{ Taizhou } & $\mathrm{C}$ & 0.806 & 0.790 & 0.780 & 0.758 & 0.757 & \multirow{3}{*}{ Anqing } & $\mathrm{C}$ & 0.719 & 0.710 & 0.742 & 0.663 & 0.579 \\
\hline & $\mathrm{D}$ & 0.711 & 0.694 & 0.693 & 0.677 & 0.677 & & $\mathrm{D}$ & 0.529 & 0.503 & 0.478 & 0.529 & 0.565 \\
\hline & Degree & $\mathrm{H} / \mathrm{H}$ & $\mathrm{M} / \mathrm{M}$ & $\mathrm{M} / \mathrm{M}$ & $\mathrm{M} / \mathrm{M}$ & $\mathrm{M} / \mathrm{M}$ & & Degree & $\mathrm{M} / \mathrm{M}$ & $\mathrm{M} / \mathrm{M}$ & $\mathrm{M} / \mathrm{L}$ & $\mathrm{M} / \mathrm{M}$ & $\mathrm{L} / \mathrm{M}$ \\
\hline \multirow{3}{*}{ Hangzhou } & $\mathrm{C}$ & 0.696 & 0.696 & 0.806 & 0.797 & 0.740 & \multirow{3}{*}{ Chuzhou } & C & 0.571 & 0.555 & 0.543 & 0.543 & 0.543 \\
\hline & $\mathrm{D}$ & 0.546 & 0.546 & 0.570 & 0.580 & 0.586 & & $\mathrm{D}$ & 0.559 & 0.550 & 0.544 & 0.543 & 0.543 \\
\hline & Degree & $\mathrm{M} / \mathrm{M}$ & $\mathrm{M} / \mathrm{M}$ & $\mathrm{H} / \mathrm{M}$ & $\mathrm{M} / \mathrm{M}$ & $\mathrm{M} / \mathrm{M}$ & & Degree & $\mathrm{L} / \mathrm{M}$ & $\mathrm{L} / \mathrm{M}$ & $\mathrm{L} / \mathrm{M}$ & $\mathrm{L} / \mathrm{M}$ & $\mathrm{L} / \mathrm{M}$ \\
\hline & $\mathrm{C}$ & 0.791 & 0.787 & 0.718 & 0.788 & 0.724 & & $\mathrm{C}$ & 0.451 & 0.439 & 0.431 & 0.428 & 0.428 \\
\hline Ningbo & $\mathrm{D}$ & 0.591 & 0.575 & 0.605 & 0.568 & 0.612 & Chizhou & D & 0.488 & 0.481 & 0.476 & 0.474 & 0.474 \\
\hline & Degree & $\mathrm{M} / \mathrm{M}$ & $\mathrm{M} / \mathrm{M}$ & $\mathrm{M} / \mathrm{M}$ & $\mathrm{M} / \mathrm{M}$ & $\mathrm{M} / \mathrm{M}$ & & Degree & $\mathrm{L} / \mathrm{L}$ & $\mathrm{L} / \mathrm{L}$ & $\mathrm{L} / \mathrm{L}$ & $\mathrm{L} / \mathrm{L}$ & $\mathrm{L} / \mathrm{L}$ \\
\hline & $\mathrm{C}$ & 0.806 & 0.791 & 0.782 & 0.784 & 0.773 & & $\mathrm{C}$ & 0.484 & 0.470 & 0.459 & 0.461 & 0.461 \\
\hline Jiaxing & $\mathrm{D}$ & 0.711 & 0.692 & 0.694 & 0.696 & 0.687 & Xuancheng & $\mathrm{D}$ & 0.508 & 0.499 & 0.493 & 0.494 & 0.494 \\
\hline & Degree & $\mathrm{H} / \mathrm{H}$ & $\mathrm{M} / \mathrm{M}$ & $\mathrm{M} / \mathrm{M}$ & $\mathrm{M} / \mathrm{M}$ & $\mathrm{M} / \mathrm{M}$ & & Degree & $\mathrm{L} / \mathrm{L}$ & $\mathrm{L} / \mathrm{L}$ & $\mathrm{L} / \mathrm{L}$ & $\mathrm{L} / \mathrm{L}$ & $\mathrm{L} / \mathrm{L}$ \\
\hline
\end{tabular}




\subsubsection{Change Patterns of Coupling Coordination Degrees}

According to the calculation data in Table 8, the value of the coupling coordination degrees of cities in the Yangtze River Delta urban agglomeration from 2008 to 2018 is further drawn into a curve, as shown in Figure 2.

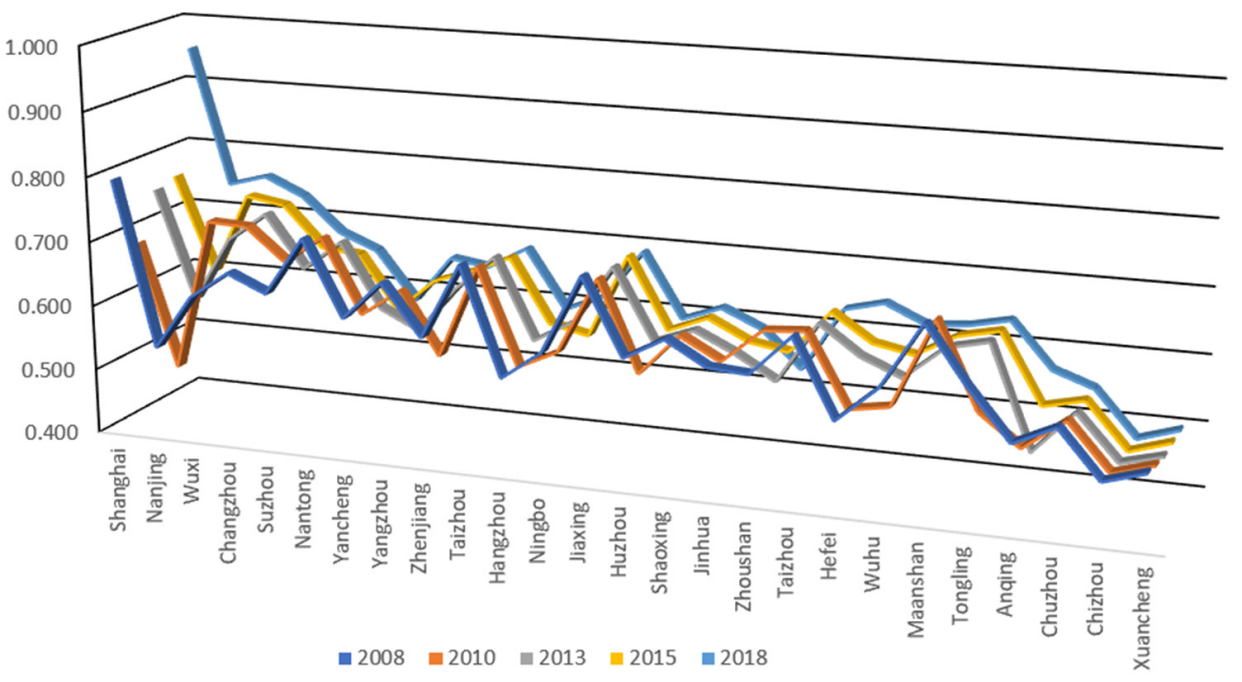

Figure 2. Change patterns of coupling coordination degrees of cities in Yangtze River Delta urban agglomeration from 2008 to 2018.

According to the analysis of the figure, the change patterns of the coupling coordination degrees of cities in the Yangtze River Delta urban agglomeration from 2008 to 2018 can be divided into five types: Type A includes Shanghai, Nanjing, Wuhu, Huzhou, Tongling, Yangzhou, Anqing, Shaoxing, and Jinhua, and the change trend of the coupling coordination degree mainly decreases first, and then increases; Type B includes Hangzhou, Hefei, and Changzhou, and its coupling coordination degree increased gradually from 2008 to 2018; Type C includes Nantong, Yancheng, Taizhou, Taizhou, Maanshan, Chuzhou, Chizhou, and Xuancheng, and its coupling coordination degree gradually decreased from 2008 to 2018; Type D includes Wuxi and Suzhou, and its change trend gradually increased from 2008 to 2010 and from 2013 to 2018, and gradually decreased from 2010 to 2013; Type E includes Ningbo, Zhoushan, Jiaxing, and Zhenjiang. Its change trend fluctuates greatly and changes frequently from 2008 to 2018 , as shown in Table 9.

We further explored the change causes and the influencing factors according to the type of change pattern:

1. As the general trend is similar, we have conducted unified research on Types A, B, and D. The coupling and coordination degrees of such cities generally show an upward trend, which can be divided into two categories: first, the population agglomeration levels of cities with relatively developed economies are at a high level and increasing, but their awareness of ecological protection is strong. Urban managers began to formulate and implement environmental protection policies and measures in an early period, and because of their strong overall economic level, they also invested a lot of support funds for the protection of the ecological environment. Taking Hangzhou as an example, the municipal environmental protection expenditure was CNY 746 million in 2008 and increased to CNY 3.6 billion by 2018. In terms of energy consumption, the energy consumption per CNY 10,000 of the GDP in Hangzhou decreased from 0.75 tons of standard coal in 2008, to 0.33 tons of standard coal in 2018, a decrease of $56 \%$. In terms of resource and environmental treatment, the urban sewage treatment rate increased from $83.24 \%$ in 2008 to $95.9 \%$ in 2018. In terms of urban green space development, the urban green space area increased from 12,791 hectares in 2008 to 46,014 hectares in 2018 , an increase of $259 \%$. Second, although some cities have not made outstanding achievements in ecological environment construction, the 
proportion of the urban population is decreasing because of various reasons, such as job opportunities and living environments, which reduces the pressure on the ecological environment and gradually tends to be coordinated between the population and ecology;

2. In C-type cities, the coupling coordination degrees are decreasing. We take Chuzhou as an example to explore the reasons. From 2008 to 2018, Chuzhou's urban population density remained basically stable. Under the condition that other cities in the Yangtze River Delta generally reduced energy consumption and pollutant emissions, Chuzhou's total water supply, sulfur dioxide emissions, industrial wastewater discharge, and smoke (powder) emissions increased by 30.3 million tons, 1948 tons, 24.92 million tons, and 8278 tons, respectively, with growth rates of $108.7 \%, 11.7 \%$, $63.4 \%$, and $34.7 \%$, respectively, far higher than the average value of the Yangtze River Delta urban agglomeration. The area of garden green space increased from 2256 hectares in 2008 to 4605 hectares in 2018, an increase of 104\%, lower than the average value of the Yangtze River Delta urban agglomeration. This shows that when the population agglomeration level remains unchanged, such cities have transited to high-pollution and high-energy-consumption industries transferred from other regions in order to achieve regional economic growth, which increases the burden on the regional ecological environment.;

3. The change trend of the coupling coordinations in E-type cities is bewildering. Among them, the interannual fluctuation of Jiaxing City is small, Zhenjiang City and Ningbo City are generally on the rise, while the population distribution of Zhoushan City shows a lack of stability due to the specific geographical conditions, so the interannual fluctuations in the population and ecological coupling coordination degrees are large.

Table 9. Change pattern types of coupling coordination degrees of cities in Yangtze River Delta urban agglomeration.

\begin{tabular}{cccc}
\hline Change Pattern & Curve Category & Region \\
\hline Type A & Decreased first and then increased & $\begin{array}{c}\text { Shanghai, Nanjing, Wuhu, } \\
\text { Huzhou, and Tongling; Yangzhou, } \\
\text { Anqing, Shaoxing, Jinhua }\end{array}$ \\
\hline
\end{tabular}

Type C

Type D

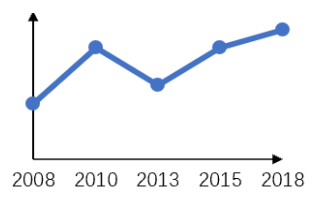

Gradually increased from 2008 to 2010,

then gradually decreased from 2010 to

2013 , and gradually increased again from 2013 to 2018.

Frequent fluctuations
Wuxi and Suzhou

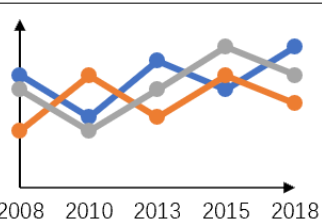

Ningbo, Zhoushan, Jiaxing, Zhenjiang 
From the basic state of the population and ecological efficiencies among the Yangtze River Delta city cluster, the population densities of Shanghai, Nanjing, and other cities are high, while the ecological efficiencies in these cities are low; Xuancheng, Chizhou, and other cities have lower population densities, and their ecological efficiencies are high. However, the coupling coordinations in Shanghai, Nanjing, and other cities are relatively high. The level of the urban development of these cities has been significantly improved, the population and ecological environment construction are mutually promoted, and the improvement in the population agglomeration degree positively improves the ecological efficiency of the city. Xuancheng, Chizhou, and other cities have relatively low degrees of coupling coordination. On the premise of maintaining economic development, their population agglomerations bring serious environmental burdens, and the ecosystem cannot completely offset the negative effects of rapid population growth.

\section{Conclusions}

Using the coupling coordination model, this research analyzes the degree of urbanization affecting the urban ecological environment from the perspective of population agglomeration. By comparing the temporal and spatial pattern changes of the coupling and coordination of population agglomeration and the ecological environment in 26 cities of the Yangtze River Delta urban agglomeration, the research reveals the change law of urban population growth on the pressure on the ecological environment, and provides a scientific basis for determining the goal of urban population development, coordinating the relationship between populations and environments in urban development, and realizing regional sustainable and high-quality development. The research shows that: The ecological efficiencies and coupling coordination degrees of cities in the Yangtze River Delta urban agglomeration show a reverse relationship as a whole. Although population agglomeration is not the most important and direct factor leading to the low ecological efficiency of some cities, it also has significant temporal and spatial distribution characteristics. In terms of the time series, from 2008 to 2018, the coupling coordination degrees of 26 cities in the Yangtze River Delta urban agglomeration showed an overall upward trend, and the population and ecological elements gradually coordinated and cooperated with each other, formed a virtuous circle, and approached the direction of high-level mutual promotion. From the perspective of the spatial dimension, there are distinct imbalances in the coupling coordination degrees among cities, and the coupling coordination degrees of some cities are still relatively low. In order to achieve the goal of regional high-quality development, further exploration on the regional coordinated development model should be developed.

The data calculation results and a theoretical analysis of the research will help to better deal with the relationship between humans and the environment in the process of urbanization, and will encourage the Yangtze River Delta urban agglomeration to achieve the goal of integrated and high-quality development. The main purpose of the research is to provide data-based support for the city administrators to adjust urban development and environmental protection policies.

Compared with other studies, the research is innovative. Firstly, it focuses on the impact of urban population agglomeration on the ecological environment, which enriches the research on population. Secondly, data envelopment analysis is combined with the coupling coordination model for analysis. While using data envelopment analysis to calculate the ecological efficiency, the coupling coordination model is used to calculate the population agglomeration degrees and ecological efficiencies, reflecting the coupling coordination relationship between them.

The research still has some limitations. Through data calculation, it shows that population agglomeration is not the most important factor affecting urban ecological efficiency; however, what is the most important factor has not been further explored. The research is only based on the perspective of population urbanization and lacks an exploration of other perspectives on urbanization. 
Author Contributions: Conceptualization, Z.X.; Data curation, Y.Y.; Formal analysis, Z.X.; Investigation, Y.Y. All authors have read and agreed to the published version of the manuscript.

Funding: This research received no external funding.

Institutional Review Board Statement: Not applicable.

Informed Consent Statement: Not applicable.

Data Availability Statement: The data presented in this study are available on request from the corresponding author.

Conflicts of Interest: The authors declare no conflict of interest.

\section{References}

1. Yu, S.; Sial, M.; Tran, D.; Badulescu, A.; Thu, P.; Sehleanu, M. Adoption and Implementation of Sustainable Development Goals (SDGs) in China-Agenda 2030. Sustainability 2020, 12, 6288. [CrossRef]

2. Liu, Z.L.; Gu, H.Y. Evolution Characteristics of Spatial Concentration Patterns of Interprovincial Population Migration in China from 1985 to 2015. Appl. Spat. Anal. Policy 2020, 13, 375-391. [CrossRef]

3. Wang, J.Y.; Jia, S.M. A Study on Promoting China'S Regional Human Capital. Chin. J. Popul. Sci. 2011, 4, 21-32.

4. Fan, C.C. Modeling interprovincial migration in China, 1985-2000. Eurasian Geogr. Econ. 2005, 46, 165-184. [CrossRef]

5. Kahn, H. World Economic Development: 1979 and Beyond. Univ. Tronto 1979, 48, 97.

6. Willard, B. The Sustainability Advantage: Seven Business Case Benefits of A Triple Bottom Line; New Society Publishers: Gabriola Island, BC, Canada, 2002.

7. Björn, S. Eco-efficiency: Creating More Value with Less Impact. World Business Council for Sustainable Development: Geneva, Switzerland, 2000; pp. 5-36.

8. Organization for Economic Cooperation and Development. Eco-Efficiency; OECD: Paris, France, 1998.

9. Figge, F.; Hahn, T. Sustainable Value Added-measuring corporate contributions to sustainability beyond eco-efficiency. Ecol. Econ. 2004, 48, 173-187. [CrossRef]

10. Park, P.J.; Tahara, K.; Inaba, A. Product quality-based eco-efficiency applied to digital cameras. J. Environ. Manag. 2007, 83, 158-170. [CrossRef]

11. Kristin, D.; Paul, E. Eco-efficiency trends in the UK steel and aluminum industries: Differences between resource efficiency and resource productivity. J. Ind. Ecol. 2005, 9, 171-188.

12. Michelsen, O.; Fet, A.M.; Dahlsrud, A. Eco-efficiency in extended supply chains: A case study of furniture production. J. Environ. Manag. 2006, 79, 290-297. [CrossRef] [PubMed]

13. Korhonen, P.J.; Luptacik, M. Eco-efficiency analysis of power plants: An extension of data envelopment analysis. Eur. J. Oper. Res. 2004, 154, 437-446. [CrossRef]

14. Lauwers, L. Justifying the incorporation of the materials balance principle into frontier-based eco-efficiency models. Ecol. Econ. 2009, 68, 1605-1614. [CrossRef]

15. Quariguasi, F.N.J.; Walther, G.; Bloemhof, J.; Nunen, J.A.E.E.; Spengler, T. A methodology for assessing eco-efficiency in logistics networks. Eur. J. Oper. Res. 2009, 193, 670-682. [CrossRef]

16. Chen, H.; Wu, Q.; Cheng, J.; Ma, Z.; Song, W. Scaling-up Strategy as an Appropriate Approach for Sustainable New Town Development? Lessons from Wujin, Changzhou, China. Sustainability 2015, 7, 5682-5704. [CrossRef]

17. Chames, A.; Cooper, W.W.; Phodes, E. Measuring the efficiency of DMU. Eur. J. Oper. Res. 1978, 2, $429-444$.

18. Banke, R.D.; Charnes, A.; CooPer, W.W. Some models for estimating technical and scale inefficiencies in Data Envelopment Analysis. Manag. Sci. 1984, 30, 1078-1092. [CrossRef]

19. Qiu, F.S.; Zhu, D.J. Eco-efficiency Indicators for China and Their Applications. Sci. Manag. Res. 2007, 1, 20-24.

20. Zhang, Q.; Deng, X.Z.; Zhou, Q. Urban Ecological Management: Concept, Mode and Resource Utilization Efficiency. China Popul. Resour. Environ. 2015, 25, 142-151. [CrossRef]

21. Chen, X.Q.; Qiao, L.J. Material Flow Analysis of Chinese Economic-Environmental System. J. Nat. Resour. 2000, 1, 17-23.

22. He, Y.Q.; Chen, L.X.; Zhou, X.G. Spatial Econometric Analysis of the Eco-Efficiency Promotion of the Yangtze RiverEconomic Zone: From the Perspective of Financial Agglomeration and lndustrial Structure Optimization. Ecol. Econ. 2016, 32, $22-26$.

23. Huang, J.C.; Fang, C.L. Analysis of coupling mechanism and rules between urbanization and eco-environment. Geogr. Res. 2003, $2,211-220$

24. Wang, X.J.; Xie, G.D.; Yue, S.P. Impact of Economic Growth and Population Aggregation on Urban Environmental Quality and Its Regional Differentiation:A Case Study of 74 Cities lmplemented the New Standard for Air Quality during the First Stage. Econ. Geogr. 2015, 35, 71-76.

25. Gao, L.; Zhang, H.Y. Progress in Research of Ecological Carrying Capacity. China Popul. Resour. Environ. 2007, $02,19-26$.

26. Yang, K.Z.; Yang, Y.; Chen, J. Ecological Footprint Analysis: Concept, Method and Cases. Adv. Earth Sci. 2000, 06, 630-636.

27. Ran, D.; Li, J.F. Study on the Spatial Coordination of Population Agglomeration and Ecological Agglomeration in China. Stat. Decis. 2020, 36, 54-57. 
28. Yang, B. Research on Regional Eco-efficiency of China from 2000 to 2006-an Empirical Analysis Based on DEA. Econ. Geogr. 2009, 7, 1197-1202.

29. Liao, C.B. Quantitative Judgement and Classification System for Coordinated Development of Environment and Economy-A Case Study of the City Group in the Pearl River Delta. Trop. Geogr. 1999, 2, 171-177.

30. Li, Y.; Li, Y.; Zhou, Y.; Shi, Y.; Zhu, X. Investigation of a coupling model of coordination between urbanization and the environment. J. Environ. Manag. 2012, 98, 127-133. [CrossRef] [PubMed]

31. Liu, J.; Dietz, T.; Carpenter, S.R.; Alberti, M.; Folke, C.; Moran, E.; Pell, A.N.; Deadman, P.; Kratz, T.; Lubchenco, J.; et al. Complexity of Coupled Human and Natural Systems. Science 2007, 317, 1513-1516. [CrossRef] 